\title{
SELF DETERMINATION DEVELOPMENT IN MULTICULTURAL SOCIETY
}

\author{
Dodi Suryana $^{1}$, Sunaryo Kartadinata, Mamat Supriatna
}

\begin{abstract}
This study aims to describe analytically multicultural self-determination. The scope of this study includes 1) a description of the multicultural self-determination of students formed through the educational process; 2) description of the way or style of regulation based on the high or low self-determination in the cultural domain. The method used was descriptive with a crossectional survey design with a sample of first semester students at UPI Bandung using a multi-stage cluster sampling technique. Power collection tools in the form of questionnaires, guidelines for observation and interviews. The results of the student research were at the level of identified regulation and the connectivity aspect was the lowest in all aspects of selfdetermination.
\end{abstract}

Keywords: Guidance and Counseling Multicultural, Self Determination counseling

JOMSIGN: Journal of Multicultural Studies in Guidance and Counseling

Website: http://ejournal.upi.edu/index.php/JOMSIGN

Permalink: http://ejournal.upi.edu/index.php/JOMSIGN/article/view/6314

How to cite (APA): Suryana, D., Kartadinata, S., \& Supriatna, M. (2018). Self Determination Development in Multicultural Society. JOMSIGN: Journal of Multicultural Studies in Guidance and Counseling, 2(2), 134-147

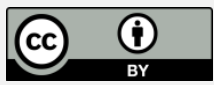

This is an open-access article distributed under the terms of the Creative Commons Attribution 4.0 International License, which permits unrestricted use, distribution, and reproduction in any medium, provided the original work is properly cited.

\section{INTRODUCTION}

Self-determination is a choice, desire, will and intention that can be encouraged, controlled and developed from culture, and Self Determination is a behavior that should be maintained and transmitted from the culture of a community (Valadez, M. J, 2001; Deci, L. E \& Ryan, M. R, 1985; Ryan, M. Ricahrd \& Deci, L. Edward, 2017; Aitken, NM, Pelletier, L. G \& Baxter, D. E, 2016). Concern in developing self-determination is evident throughout human life theologians, philosophers, scientists, psychologists, psychologists, and doctors have researched the concept of self-determination, during the Middle Ages, two important developments took place and began to carry the study of selfdetermination as a concept to be considered and developed to form individual behavior in the face of multicultural community life.

${ }^{1}$ Universitas Pendidikan Indonesia; dodisuryana@upi.edu 
Basic considerations of self-determination shape individual behavior in dealing with the life of multicultural societies, namely first some theories position fundamental tendencies regarding the movement direction of development from heteronomous to autonomous in behavioral determination, secondly movements in the context of cognitive theories that shift the focus from associative ties to decision making main concepts of behavior direction. The results of the study of the direction of the development of selfdetermination, first Maslow's theory $(1943 ; 1955)$ underlines that motivation theory (the achievement of self-determination) uses the concept of selfactualization, representing each individual looking for their unique potential to become capable and autonomous individuals in showing their functioning, second Rogers (1963) explains the activities of individuals in their lives can be understood as the tendency of actualization that is maintained and enriched by individuals and the concept of self-actualization still emphasizes the importance of choices and other constructs related to self, third Loevinger (1976a), in his theory of ego development, using a structural perspective and underlining the stages in which a person moves developmentally towards more integrated and autonomous functioning, the fourth Shapiro (1981) with the psychoanalytic approach discusses autonomy within the scope of psychological structure flexibility, by focusing on to focus on the structure contained in autonomy, and its benefits in understanding ego adaptation, fifth Lewin (1951b) and Tolman (1932) are influential experts in the movement of cognitive theory, which explains the concepts of self and control (intention / desire) as the main motivational constructs / behavior related to decision making, as well as behavior is a function of expectations of things that happen in the future, individuals have control or not control the desired results in the future, being a very important point, and most recently, the sixth Edward L. Deci \& Richard M. Ryan, 1985; 2017; Cutre, G. D., et al, 2016) that self-determination is a very important element in the life of a multicultural society because it is one of the factors that allows individuals to (1) have the ability and opportunity to communicate and make personal decisions in dealing with the life of multicultural society; (2) has the ability to express choices, exercise control over the type and intensity of support received in the lives of multicultural societies; (3) has the power to control the resources within himself in order to obtain the desired results from an act in the presence of a multicultural society; (4) has the opportunity to participate and contribute to the multicultural community 
environment; (5) can advocate for themselves and others through various activities in the life of multicultural society; and 6) can achieve wellness (Davids, LE, Roman, V. N and Kerchoff, J. L, 2016; Deci, L. E \& Ryan, M. R, 2008; Dehhan, RC, Hirai, T., and Ryan , M. R, 2015; Martela, F and Ryan, M. Richard, 2015; Rahman, J, R., Hudson J., Ntoumani, TC, and Doust HJ, 2015).

The development of self-determination encourages individuals to fulfill three aspects of basic needs and has the skills to deal with the lives of multicultural societies. The three aspects of self-determination are explained in detail as follows: a) Competence, that is, individuals need to feel they have mastery of the skills that enable individuals to deal effectively with challenges, problems and obstacles in their environment, which are characterized by their ability to think and act flexibly, competently and professional, has competitive advantage, has healthy, good, true, smart, creative, hard working, honest, responsible, consistent, commitment, perseverance and perseverance value; $b$ ) Connectedness (relatedness), namely individuals experiencing effective social skills and having meaningful social relations, connected in interaction with people in their environment, which is characterized by the ability to communicate well, make decisions and be able to negotiate; and c) Independence (autonomy), that is, individuals can choose/act and act / agency that is good, right and meaningful following their actions, which are characterized by having strong conviction, pleasure, optimism, determination and high spirits (Deci \& Ryan, 1985; Niemiec, Chirstopher, Ryan \& Deci, 2010; Lynch, 2010; Amoura, C., et al, 2015; Jang, H., Reeve, J \& Halusic, M, 2016).

The generation of life in higher education now, there are still many students who have low self-determination, which shows behaviors such as difficulty in making a decision, weak coordination with peers or educators, weak self-management, skipping college, being bored in studying, lazy to do assignments, not yet having pleasure in doing all activities/tasks, criticizing others and yourself, often thinking negatively and not yet addressing thinking and acting creatively (Lynch, Vansteenkiste \& Ryan, 2010; Deci \& Ryan, 2000; Ryan, et al, 2011).

The results of the American College Health Associations research (2006, in Misra \& McKean, 2000) stated that 97,357 students showed that $32 \%$ of students had a low determination they showed behavior unable to complete assignments well and get lower GPA. The results of research conducted by Solomon \& Rothblum (1984) state that indications of students experiencing 
academic delays or study delays (congestion) are caused by students having a lack of development of self-determination, so they experience a study period of 5 years or more. Based on data from the planning and information system administration bureau (BAPSI) at one of the state universities in Indonesia, it is shown that $57 \%$ of $2004 / 2005$ students are still registered as students in 2010/2012 or study period is more than 6-7 years, so these students are indicated experiencing late completion of studies (congestion) (Rumiani, 2006). Besides they are individuals who have difficulty in completing studies. Research Results Litalien, D., \& Guay, F (2015) states that if individuals who have difficulty completing studies are left alone, they experience frustration (Cordeiro, $\mathrm{P}$ et al, 2016; Nishimura, T., and Suzuki, T, 2016 ), Depression (Leow, K., Lee, M., and Lynch, F. M, 2016; Yu, C., Li., Wang, S \& Zhang, W, 2016) or threatened with dropout.

Self-determination is owned by each individual, but the diversity of the spectrum of needs and milestones of development of different individuals requires service diversification, cultural sensitivity, cultural awareness, and cultural intelligence. Cultural intelligence for the development of selfdetermination encourages individuals to enter tacit knowledge is one form of explicit knowledge, which is difficult to be articulated, explained, or expressed without real examples in daily life and knowledge that is not expressed or cannot be understood without being expressed expressly directly (Collins, 2010; Guthrie, 1996). In epistemology and ontology, tacit knowledge emphasizes creative interaction (Yoshimichi, A, 2012; Toom, 2012; Berry, R, T., Rodggers, M. W., Markland, D \& Hall, R. C, 2016). Feest Study Results, U (2016) explains that tacit knowledge plays an important role in reasoning and decision making about something important in his life. Study of Sternberg \& Horvath (1999; Sternberg, R.J., \& Horvath, J.A. (eds), 1999) explains that tacit knowledge serves as the key to intelligent behavior in a practical setting that includes the ability of individuals to apply their skills to overcome various life problems they face.

Results of a study by Sternberg (2005; Lyra, P. M 2016; Dube, R.A., et al, 2015) tacit knowledge intelligence includes the application of intelligence components into experience to (1) adapt itself to the environment; (2) choose, decide, see a better environment following their needs, skills, and desires; and (3) change their environment to suit themselves. This practical intelligence / tacit knowledge is called the power of adaptation or high adaptability as 
personal, professional, and optimal personal development goals (Kartadinata, 2016).

One of the efforts to develop skills in self-determination aspects is through education. Guidance and counseling as part of education have the aim of assisting individuals in developing self-determination as part of the ability of multicultural societies. Guidance and counseling facilitates individuals in a variety of possibilities and direction of goals to monitor, direct and produce thoughts, feelings, and actions that are planned and adapted to accomplish their desired goals/self-determination achievement (Kartadinata, 2016; 2016; Deci \& Ryan, 1985, 2017; Guay, F., Valois, P., Falardeau, E., and Lessard, V, 2016).

Based on the studies and research results described in the previous subsections, it can be understood that self-determination is an important aspect as a determinant of the success of individuals in the lives of multicultural societies, various research studies show that education as a correlative variable in selfdetermination is a very dynamic and characteristic aspect for follow-up / developed, so research is still needed with educational variables, especially on the development of self-determination in multicultural societies.

\section{METHOD}

The research design used was a survey design, with a cross-sectional design, namely by collecting data at one point in time (Creswell, 2012, p.377). This research design was used to provide information about self-determination in a short-lived multicultural society. The data collection steps were taken in the following steps: (1) opening the meeting with greetings and brief introductions; (2) convey the intent and purpose of filling in the measuring instruments; (3) checking presence; (4) distributing measuring instruments with answer sheets; (5) explains how to fill in; (6) provide the opportunity for respondents to ask questions; (7) invite respondents to answer questions; (8) collecting answer sheets and questions; and (9) closed the meeting, thanking and greeting.

Furthermore, the results of quantitative data are processed and analyzed with descriptive statistical procedures in the form of knowing the overall average and the average of each aspect of self-determination. The results of qualitative data in the form of observations and interviews with students and teachers were analyzed with theme analysis techniques referring to the grand theory and other sources of reference that support / are relevant. 


\section{RESULTS AND DISCUSSION}

In general, the profile of the level of self-determination of UPI undergraduate students in 2017 at the university level can be seen in table 1 .

Table 1

Profile of Self-Determination Level for UPI Undergraduate Students 2017 University Level

\begin{tabular}{clcc}
\hline No & Self Determination Rate & $\mathbf{N}$ & Proportion \\
\hline 1 & Amotivation & 0 & 0 \\
\hline 2 & Eksternal Regulation & 2 & 1,667 \\
\hline 3 & Introjected Regulation & 6 & 5 \\
\hline 4 & Identified Regulation & 59 & 49,167 \\
\hline 5 & Integrated Regulation & 39 & 32,5 \\
\hline 6 & Intrinsic Regulation & 14 & 11,667 \\
\hline \multirow{2}{*}{ total } & $\mathbf{1 2 0}$ & $\mathbf{1 0 0}$ \\
\hline
\end{tabular}

Self-determination of UPI undergraduate students in 2017 is mostly at the level of identified regulation and a small portion is at the level of external regulation and introjected regulation. From the proportions, the level of student self-determination spreads on five levels, with the order of the level of identified regulation, integrated regulation, intrinsic regulation, introjected regulation, and external regulation.

The overall research findings of students are mostly in the category of identified regulation, this is following the results of the study of Deci \& Ryan (1985) individuals who have a level of identified regulation is action occurring on behalf or relevance to individual goals or departing from the relevance of individuals in acting. The results of studies and research by Deci \& Ryan (1985; Carter, A. J, 2011) explain that the category identified regulation is a low category or students who have inadequate self-determination, students will show a behavior that is not optimal in dealing with various demands, problems or academic or non-academic pressures and negative impacts on the smooth completion of studies that can cause them to respond to problems destructively (Thoresen \& Eagleston; in Roberson, 1985, p.5).

Associated with self-determination theory Deci \& Ryan (1985; Britton, C. P, Williams, C. G \& Conner, R. K, 2008) and the results of the opinion of Witriani, et al (2007) the findings of this study imply that the ability of students to act and changing the cognitive that will affect the level of self-determination that is changing the dynamics of students regulate self-management in the face 
of certain tasks. The more individuals internalize and assimilate values into themselves, the more individuals will experience greater autonomy in their behavior (the more self-determined).

Glass, Singer \& Miller (1980; in Deci \& Ryan, 1985) study states that when individuals believe and believe that they are in control of the demands in their environment, individuals can act more effectively, developing selfdetermination with self-approval., actions taken with self-reflection become interesting, beneficial to oneself and direct pleasure, voluntary, commitment, active work (Niemiec, Ryan \& Deci, 2008; Joussemet, Mireille, Renne \& Koestner, 2008). In line with the research of Miller and Rollnick (2002; in Ryan \& Deci, 2008) explains that individuals who have high determination, because individuals perceive changes based on will, individuals feel able to make positive changes with their abilities, and individuals have readiness, give high priority to making changes compared to other priorities.

Deci and Ryan's research (1991) explains that the dimensions of individual behavior range from being determined (having self-determination) to being controlled (driven by interpersonal or intrapsychic demands) that range is distinguished using the concept of locus of causality (Decharms, 1968; Ryan \& Connel, 1989; in Deci, et al, 1991). Determined behavior is the behavior of an individual believing that the cause of the behavior originates from within himself, while when behavior is controlled, the individual believes that the cause of the behavior originates from outside himself. An important point in these differences is that both determined and controlled behavior is both motivated and intentional, but the regulatory process is very different. Besides, the quality of the experimental and behavioral components in it is different.

Behavior that is accompanied by self-determination tends to be more attached to individuals, makes individuals more motivated and has an internal locus of control. If the individual has self-determination, the individual will be more consistent with his actions, socially responsible, show perseverance and persistence in achieving goals, have higher self-awareness and self-adjustment ability (O'Connor \& Vallerand, 1994).

Specifically, the average in terms of three aspects of self-determination can be seen in table 2 .

Table 2

Average Judging From the Aspects of Student Self Determination

\begin{tabular}{llc}
\hline No & The Aspect of Self Determination & Mean \\
\hline A & Competence & 6.24 \\
\hline B & Connectedness & 6.49 \\
\hline
\end{tabular}




\begin{tabular}{lll}
\hline $\mathrm{C}$ & Independence & 5.27 \\
\hline
\end{tabular}

Table 2 shows, spread out on each of the three aspects in the order of aspects of connectedness, aspects of competence and aspects of independence. The independence aspect refers to a low average of all aspects of selfdetermination.

The research findings explained that the independence aspect is smaller than the competency and connectedness aspects, the findings are examined from the results of classroom observations explained that some behaviors have not been optimally developed in the connectivity aspect. Indications of suboptimal behavior exhibited by students in the aspects of connectedness during class and interviews marked by students lacking the enthusiasm to work on college assignments, the number of lectures burdens some students tend to avoid doing and doing harmful actions (skipping lectures, not listening to the opinions of friends or lecturers), students have not been fully supported by parents for college in higher education, have not been given the freedom to make choices regarding lectures by parents, have not received awards from parents because of good achievements, have not received guidance from parents about lectures, lack of student interest to organize in inside or outside the campus environment so that students lack the opportunity to interact with senior or lecturer level, students tend to do activities after finishing from campus to pamper themselves by watching tv at home or home.

The findings of this research are in line with the research study of Deci, et al (1991) on students, resulting in students lacking or low self-determination caused by students indulging themselves and lacking motivation or interest in doing all activities or activities on and off-campus. the findings of this study are following Maslow (in Deci, et al, 1991) explaining that independence is one of the characteristics possessed by people driven by the motivation to develop as primary satisfaction. They do not depend on the outside environment like other people and rely more on their potential and abilities in efforts to develop and sustain themselves.

Furthermore, Loman, et al (2010) initiated a practical guideline for the development of self-determination based on the assumption that individuals who have high self-determination are causal agents are actions that have clear goals and objectives and specific requests or orders from the individual itself (proxy agent). The research findings are strengthened from the results of a study by Loman, et al (2010) looking at self-determination in a cultural context as a 
psychological construct that refers to actions caused by oneself to enable someone to act volitionally based on their desires. Volitional in this case refers to the capability of consciously generating choices, decisions, and intentions. Self-determination in the cultural context there are several activities in the form of interventions that focus on: (1) efforts to build the capacity of individuals to take actions that lead to higher levels of self-determination, more autonomous regulatory styles (eg problem solving, decision making, goal setting, and selfadvocacy, (2) efforts to modify the context or environment in such a way as to encourage someone to do certain things in his life, and (3) efforts to provide support that can develop self-determination such as technology and accommodation.

Besides, the results of Deci and Ryan's research (2017) show high and low competence, independence and connectedness depending on cultural norms and practices, horizontal collectivity practices that place a collective society and treat individuals equally / equally and cultural values that are shown to be important and equal, and practices vertical collectivity, culture emphasizes that collective needs arise before individuals recognize a place, and vertical individualist cultures support the efforts of individuals to gain recognition and competitive differentiation to achieve positions of power and influence over others.

In line with the study by Deci and Ryan (1985) when individuals think carefully about decisions made, and dare to bear the risk of decisions made, there are types of individuals who will do something for pleasure and satisfaction because they know something, individuals do something for pleasure and satisfaction when trying to get things done as well as individuals doing something to feel stimulating sensation.

\section{CONCLUSION}

The findings obtained by the development of self-determination of UPI undergraduate students in 2017 in four Departments are in the category of identified regulation, individuals who have a level of identified regulation are individuals who take action to occur in the interests or relevance of individual goals or depart from the relevance of individuals in acting. Furthermore, the identified category is a low category or students who have inadequate selfdetermination, students will exhibit suboptimal behavior in dealing with various demands, problems or academic or non-academic pressures and harm the smooth completion of studies that can cause them to respond to problems by 
destructive. In the aspect of self-determination students have the aspect of connectedness ranks lowest in all aspects of self-determination.

\section{REFERENSI}

Aitken, N.M., Pelletier, L. G \& Baxter, D. E (2016) Doing the difficult stuff: Influence of self-determined motivation toward the environment on transportation pro-environmental behavior. Journal Ecopsychology, Vol 8 pp. 153-162.

Amoura, C., et al (2015) Autonomy-Supportive and Controlling Styles of Teaching Opposite or Distinct Teaching Styles. Swiss Journal of Psychology, Vol 74 (3), 141-158.

Berry, R, T., Rodggers, M. W., Markland, D \& Hall, R. C (2016) Moderators of Implicit-Explicit Exercise Cognition Concordance. Journal of Sport \& Exercise Psychology. https://dx.doi.org/10.1123/jsep.2016-0174.

Britton, C. P, Williams, C. G \& Conner, R. K. (2008). Self-determination theory, motivational interviewing, and the treatment of clients with acute suicidal ideation. Journal Of Clinical Psychology, 64 (1), pp. 52-66 (10 November 2016).

Carter, A. J. (2011). Changing light bulbs: practice, motivation, and autonomy. the counseling psychologist. Sagepub. Vol 39 (2), pp. 261-266 (10 November 2016).

Cordeiro, P et al (2016) The Portugueses Validation of The Basic Psychological Need Satifaction and Frustration Scale: Concurrent and Longitudinal Relations to Well-Being and lll-being. Journal Psychologica Belgica. Vol 56 (3), 193-209. https://dx.doi.org/10.5334/pb.252

Cutre, G. D., et al (2016) Understanding the Need for Novelty From the Perspective of Self Determination Theory. Journal Personality and Individual Differences, Vol 102, 159-169.

Collins, Harry. (2010). Tacit and explicit knowledge. Chicago: The University of Chicago Press

Davids, L. E., Roman, V. N and Kerchoff, J. L (2016) Adolescent goals and Aspirations in search of Psychological Well-being: From the Perspective of Self- Determination Theory. Journal Psychological Society of South Africa, 1-12. Htpps://doi. 10.1177/0081246316653744. 
Deci, L. E, \& Ryan, M. R. (1985). Intrinsic motivation and self-determination in human behavior. New York: Plenum.

Deci, L. E, dkk. (1991). Motivation and education: the self determination perspective. Educational psychologist. lawrence erlbaum associates, Inc. Vol 26 (3\&4), pp. 325-346 (9 Desember 2016).

Deci, L. E \& Ryan, M. R. (2000). Intrinsic and extrinsic motivations: classic definitions and new directions. Contemporary Educational Psychologhy. 25, pp. 54-67 (10 Desember 2016).

Deci, L. E \& Ryan, M. R. (2008). Self determination theory: a macrotheory of human motivation development, and health. Canadian Psychology. Vol 49 (3), pp. 182-185 (3 Desember 2016).

Dehhan, R. C., Hirai, T., and Ryan, M. R (2015) Nussbaums's Capabilities and Self-Determination Theory's Basic Pschological Needs: Relating Some Fundamentals of Human Wellness. Journal Happines Study. Vol 17, 2037-2049. https://doi 10.1007/s10902-015-9684-y.

Dube, R.A., et al (2015) The Relations Between Implicit Intelligence Beliefs, Autonomous Academic Motivation, and School Persistence Intentions: A Mediation Model. Journal Social Psychology Education, Springer. Vol 18, 255-272. Htpps://doi 10.1007/s11218-014-9288-0.

Feest, U (2016) The Experimenters' regrees reconsidered: Replication, Tacit Knowledge, and The Dynmics of Knowledege Generation. Dalam Journal Studies in History and Philosophy of Science Vol 58.,pp 34-45. Halaman tersedia: http://onlinelibrary.wiley.com [2 Desember 2016].

Guay, F., Valois, P., Falardeau, E., and Lessard, V (2016) Examining the Effects of a professional Development Program on Teachers' pedagogical pratices and Students' Motivational Resource Achievement in Written French. Journal Learning and Individual Differences, Vol 45, 291-298.

Guthrie, Steven. (1996). The role of tacit knowledge in judgement and decision making. Online: available in ERIC (ED404083.

Jang, H., Reeve, J \& Halusic, M (2016) A New Autonomy-Supportive Way of Teaching That Increases Conceptual Learning: Teaching in Students' Preferred Ways. The Journal of Experimental Education, Vol 84 (4), 686701. https://doi.10.1080/00220973.2015.1083522. 
Kartadinata, Sunaryo (2016). Reveal The Veil Of Guidance And Counseling In Pedagogic Effort. UPI Press.

Leow, K., Lee, M., and Lynch, F. M (2016) Big Five Personality and Depressive Symptoms: A Self-Determination Theory Perspective on Students' Positive Relationships With Others. Journal Visitas Online.

Loman, S. dkk. (2010). Promoting self-determination: a practice guide. University of Oregon.

Lynch, F. M, Vansteenkiste, M \& Ryan, M. R. (2010). Autonomy as process and outcome: revisting cultural and practical issues in motivation for counseling. The counseling psychology, 39 (2), pp. 286-302. Retrieved from http://tcp.sagepub.com/content/39/2/286 (9 Desember 2016).

Lyra, P. M (2016) A Development and Process Approach to "Choice Categories": Imagination and "Tacit Knowledge". Dalam Journal Integr Psych Behav, Vol 50, pp 392-400. Halaman tersedia: http://onlinelibrary.wiley.com [2 Desember 2016].

Lynch, F. M. (2010). Basic needs and well-being: a self determination theoryview.Retrievedfrom:http://counselingoutfitters.com/vistas/vistas10 /Article 70. pdf (22 November 2014).

Litalien, D., \& Guay, F (2015) Dropout Intentions in PhD Studies: A Comprehensive Model Interpersonal Relationships And Motivational Resources. Journal Contemporary Educational Psychology, Vol 41, 218 231. http://dx.doi.org/10.1016/j.cedpsych.2015.03.004.

Martela, F and Ryan, M. Richard (2015) The Benefits of Benevolence: Basic Psychological Needs, Beneficence, and The Enhancement of WellBeing. Journal Of Personality. https://doi 10.1111/jopy.12215.

Misra, R \& McKean. (2000). college students' academic and its relation to their anxiety, time management, and leisure satisfaction. American Journal of Health Studies, Vol. 16(1), pp. 41

http://classroom.synonym.com/academic-its-relation-anxiety-collegestudents-2777.html (11 Desember 2014).

Niemiec, P. C, Ryan, M. R \& Deci, L. E. (2010). Self determination theory and the relation of autonomy to self regulatory processes and personality development. New York: Blackwell Publishing. 
Nishimura, T., and Suzuki, T (2016) Basic Psychological Need Satisfaction and Frustration in Japan: Controlling For The Big Five Personality Traits. Journal Japanese Psychological Research, Vol 58 (4), 320-331. https://doi.10.1111/jpr.12131.

O’Connor, P. B \& Vallerand, J. R. (1994). Motivation, self-determination, and person-envirnment fit as predictors of psychological adjustment among nursing home residents. Psychology and Aging, Vol 9 (2). pp. 189-194 (5 November 2016).

Pintrich, R. P. (2003). A motivational science perspective on the role of student motivation in learning and teaching context. Journal of Educational Psychology, 95 (4), pp. 667-686 (15 Oktober 2016).

Rahman, J, R., Hudson J., Ntoumani, T.C., and Doust H. J., (2015) Motivational Processes and Well Being in Cardiac Rehabilitation: A Self Determination Theory Perspective. Journal Psychology Health \& Medicine. Vol $\quad 20 \quad$ (5), http://dx.doi.org/10.1080/13548506.2015.1017509.

Roberson, J. B. (1985). The effect of stress inoculation training in a classroom setting on state-trait anxiety level and self concept of early adolescents. (Dissertation). Texas : Graduate Faculty Of Texas Tech University.

Ryan, M. R \& Deci, L. E. (2008). A self determination theory approach to psychotherapy: the motivaional basic for effective change. Canadian Psychology, Vol 49 (3), pp. 186-193 (13 Desember 2016).

Ryan, M. R, dkk. (2011). Motivation and autonomy in counseling, psychotherapy, and behavior change: a look at theory and pratice. The Counseling Psychologist. Vol 39 (2), pp. 193-260 (10 Desember 2016).

Ryan, R. M., Deci, E. L \& Vansteenkiste, M (2016) Autonomy and autonomy disturbances in self developmenta and psychopatahology: Research on motivation, attachment, and clinical process, In D Cicchetti (Ed). Dalam journal Developmental psychopathology vol 1, pp. 385-438.

Ryan, M. Ricahrd \& Deci, L. Edward (2017) Self determination theory: Basic Psychological Needs in Motivation, Development and Wellness. New York: The Guilford Press. 
Solomon, L.J., \& Rothblum, E.D. (1984). Academic procrastination: frequency and coginitive behavioral correlates. Journal of Counceling Psychology, 31 (4), pp. 503-509 (18 November 2014).

Sternberg, R.J., \& Horvath, J.A. (eds). (1999). Tacit knowledge in professional practice: Researcher and practitioner perspectives. Mahwah, New Jersey: Lawrence Erlbaum Associates, inc.

Toom, A (2012) Considering The Artistry and Epistemology Of Tacit Knowledge And Knowing. Dalam Journal Educational Theory. Vol 62 No 6 pp.621-640. Halaman tersedia: http://onlinelibrary.wiley.com [2 Desember 2016].

Valadez, M. J (2001) Deliberative Democracy, Political Legitimacy, and Self Determination in Multicultural Societies. United States of America: Westview Press The Persesus Books Group.

Wichmann, S. S. (2011). Self determination theory: the importance of autonomy to well being across cultures. Journal of Humanistic Counseling. 50, pp. $16-26$.

Yu, C., Li., Wang, S \& Zhang, W (2016) Teacher Autonomy Support Reduces Adolescent Anxiety Depression: An 18-Month Longitudinal Study. Journal of Adolescence, Vol 49, 115-123. http://dx.doi.org/10.1016/j.adolescence.2016.03.001.

Yoshimichi, A (2012) An Examination of the SECI model in Nonaka's in terms of the TEAM linguistic Framework. 